\title{
A Case Study of Thermal Comfort in a Temporary Shelter
}

A Case Study of Thermal Comfort in a Temporary Shelter

Received 2021/06/04

Accepted after revision $2021 / 08 / 30$

*Corresponding author: jurgis.zemitis@rtu.lv

$\Gamma$ arossef $h t t p: / / d x . d o i . o r g / 10.5755 /$ j01.sace.29.2.29240

In Latvia to perform COVID-19 tests as well as for temporary shelters in case of a local disease outbreak the persons were located in special tents. Such practice was not only performed locally but also in other countries like the USA, UK, Russia, etc. The wide usage of tents was possible as the outbreak happened during the warm period of the year. At the same time, the indoor climate of tents can be quite unbearable during the warm summer days. Also, the situation was not getting better as fast as the prognosis, and the crisis was still ongoing during the winter period. Therefore, to test the thermal comfort of such temporary shelter's measurements were performed. The thermal comfort was measured in a tent from 27th May to 28th September 2020. The data was logged with three different measuring devices inside of the shelter as well as outside air parameters like temperature and solar radiation was logged. The results show the rapidly changing indoor temperature which reaches $40^{\circ} \mathrm{C}$ during the daytime and falls to $10^{\circ} \mathrm{C}$ at night. The data of the globe thermometer to analyze the influence of radiation from tent canvas was also studied and showed that there is no noticeable heat radiation from external walls. The PMV measurements showed that the thermal comfort is very low as the PMV values were outside the range of -1 to 1 for $57 \%$ of the time. The influence of the precipitation was also noted, and the results showed that the adiabatic cooling effect is very variable but in general does not noticeably change the indoor temperature, the average temperature decrease was only $1{ }^{\circ} \mathrm{C}$, but for a specific case it reached $10^{\circ} \mathrm{C}$.

Keywords: COVID-19, temporary shelter, tent, thermal comfort.

The year 2020 was lived in the sign of COVID-19 pandemic. This affected the whole world, caused many deaths, and changed the everyday life of almost every person. As the hospitals in many countries were not capable to take up the high number of patients and at the same time ensure safe testing of inhabitants many temporary shelters were installed. In Latvia to perform COVID tests as well as for temporary shelters in case of a local disease outbreak the persons were located in special tents. Such practice was not only performed locally but also in other countries like the USA, UK, Russia, Spain, Italy, etc. Such shelters could also be used to set up mobile vaccination points as this becomes the major weapon to fight the pandemic. Also, tent-like shelters are often used in cases of refugee camps. At the end of the year, 2014 more than eight million people were living in encampments (UNHCR 2014) in addition to this more than nineteen million new people were displaced due to natural hazards in 2015 (IDMC 2017). By the year 2021, the number of refugees has grown to new heights and is estimated to be 26.4 million people, from whom approximately 3 million are located in Europe (UNHRC 2021).

\section{Introduction}

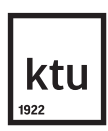

Journal of Sustainable Architecture and Civil Engineering Vol. 2 / No. 29 / 2021 pp. $139-148$ DOI 10.5755/j01.sace.29.2.29240 
The wide usage of tents in the first month of the pandemic was possible as the outbreak started in spring and went on during the warm period of the year. At the same time, the indoor climate of tents can be quite unbearable during the warm summer days. Also, the situation is not getting better as fast as anticipated and the crisis was also ongoing during the winter period and following summer. This means that some type of climatic systems must be installed for the tent-type shelters in cold climate countries to heat them during cold periods and cool during the summertime. However, it is necessary to measure the thermal comfort parameters for such a temporary shelter to see how it can be improved.

Thermal comfort is defined as a state of satisfaction with the thermal conditions of the environment. It is also considered as a lack of negative feelings caused by the thermal effects of the environment. Assurance of thermal comfort requires the thermal stability of the human through maintenance of the thermal balance between body heat production and loss. (Matusiak 2010; Rupp, Vásquez, and Lamberts 2015; Van Hoof 2008; De Dear et al. 2013). The thermal comfort is often expressed in PMV and PPD indices, however, the existing studies (Susanti 2015; Bouden and Ghrab 2005; Nicol, Humphreys, and Roaf 2012) show that in the case tents are located in a hot and humid area the results of PPD index incorrectly assess how the persons feel and PMV-PPD models have some limitations. This is backed up by a separate investigation in Tianjin (Yang et al. 2016). It shows that persons like soldiers and officers can adapt to the thermal environment and tolerate wider temperature fluctuations. The thermal comfort is affected by a complex interaction of various environmental aspects as well as characteristics of the tent - used materials, heating systems, location, natural ventilation options, etc. (Potangaroa and Hynds 2008). As thermal comfort is linked to the state of mind the stressful conditions of lockdown and pandemic could also affect the evaluation of the environment. This was studied in a paper (Thapa et al. 2021) which found that the productivity and overall comfort declined with the increase in the days of lockdown, which signifies the psychological impacts of the restrictions. However, the results were not conclusive as no real environmental measurements were possible, therefore it was not possible to make further analysis of thermal comfort. Also, the age of the occupants can play a role in how the thermal comfort is felt as indicated in a study (Dobravalskis, Šeduikyte, and Didz lariekyte 2020) regarding elderly care centers and for children in daycare centers (Kuusk et al. 2019). The influence of natural air infiltration must be taken into account, although this is a complex calculation a dynamic grid model method has been developed and validated in a study (Bilous, Deshko, and Sukhodub 2020). The study established that the energy consumption of a building at the normative value of the air exchange rate and the calculated value of the natural component of the air exchange rate could differ by up to $50-75 \%$.

For thousands of years, a tent has probably been the basic form of emergency shelter. Tents are relatively quick and simple to erect, they are more acceptable to host nations than more permanent forms of shelter, and remain flexible for later changes to planning or relocation (Susanti 2015). However, the tents are different, with various shapes and made of specific fabrics. A study (Gooijer et al. 2019) analyzed the influence of the material of tents on thermal comfort and it showed that the fabric has no influence on the heat transport at the same time it can strongly affect the water vapor transport and that the condensation cannot be prevented. In a study (Obyn, van Moeseke, and Virgo 2015) a model was created for predicting the thermal behavior of the family shelter for emergencies used by the UNHCR, the IFRC, and ICRC. The results of the model were relevant and may reproduce the actual behavior of a tent, as well for Belgium than for other climatic conditions. The deviation between calculated and measured internal temperatures was in ranges between $1.6^{\circ} \mathrm{C}$ and $2.5^{\circ} \mathrm{C}$.

An existing study (Crawford, Manfield, and McRobie 2005) that focused on the thermal comfort of a tent located in a cold climate showed that there is a dramatic variation in temperature with height, 
which is undesirable. Also, the stratification would be a problem especially during nighttime which would lead to low temperatures and the necessity to rely on personal insulation. In theory, this could be improved by increased air mixing through ventilation. A study (Rachel 2001) has also tested a liner that can be easily installed in a tent and provides good insulation and reduced heat loss. However, the stratification problem still stands, and floor insulation must be provided. Another study (Manfield, Ashmore, and Corsellis 2004) regarding tents in cold climate states that liners can have a significant effect upon improving thermal comfort inside a tent but a more holistic approach must be applied and future research should be upon how to involve displaced persons in equipping their shelter. For example, through the use of sleeping bags. A previously published paper (Huang 2008) analyses six models for predicting temperature ratings of sleeping bag systems depending on the skin temperature and metabolic rate. Thermal comfort through sleeping bag and clothing insulation adaption can ensure that the thermal comfort is kept even in high altitude hiking under extreme weather conditions (Cena, Davey, and Erlandson 2003).

The thermal discomfort problem occurs also during hot periods of the year. According to a study (Albadra et al. 2017), the comfort temperature ranges from $17.2^{\circ} \mathrm{C}$ to $28.4^{\circ} \mathrm{C}$ if the adaptive model is applied. Still, the temperature in the tents and refugee camps can be outside this range. In general, the existing tents even with improvements are not capable to ensure a pleasant indoor thermal environment (Poschl 2019) and therefore must be equipped with additional HVAC systems. Higher comfort parameters can be achieved if the temporary shelter is developed not as a tent but as a mobile energy shelter house (Kim et al. 2015), however, this is a more complex and expensive solution and is often not possible in a short period of time.

In this paper, we aim to study the thermal comfort of a temporary shelter located on the $56^{\text {th }}$ parallel in northern Europe during the summer period. Measurements of outside and indoor temperatures at various heights are performed and PMV values are calculated. The data is analyzed to see how the indoor temperature changes depending on the outside parameters such as temperature, solar radiation, and precipitation. The information is needed for further studies and for the development of a Mobile Modular Energy Unit (MMEU) which would be used to ensure pleasant indoor thermal comfort through ventilation and air cooling.

The study was conducted from $27^{\text {th }}$ May to $28^{\text {th }}$ September 2020 , which corresponds to the summer and early fall seasons. The measurements were done in a tent with a floor area of $54 \mathrm{~m}^{2}$ and an approximate volume of $100 \mathrm{~m}^{3}$ (see Fig. 1). The studied tent was a military type. The external fabric of the tent was of dark green, waterproof PVC material with the option to add an additional cotton insulation layer. The estimated air permeability of the tent was not measured but according to existing publications (Cornaro et al. 2015) could be about $35 \mathrm{~m} 3 / \mathrm{h} / \mathrm{m}^{2}$ at a pressure of $50 \mathrm{~Pa}$ while thermal conductivity $\lambda$ of the external material is $27 \mathrm{~W} / \mathrm{mK}$.

The data was logged with three different measuring devices -4 channel thermometer PCE-T390 (Accuracy at $23^{\circ} \mathrm{C} \pm 0.4 \%+1{ }^{\circ} \mathrm{C}$ ) located in the middle of the tent at heights $0.1,1.1,1.8$, and $2.2 \mathrm{~m}$, two temperature/relative humidity loggers Hobo UX100-023 (Accuracy: $\pm 0.21^{\circ} \mathrm{C}$ from $0^{\circ}$ to $50^{\circ} \mathrm{C}$;

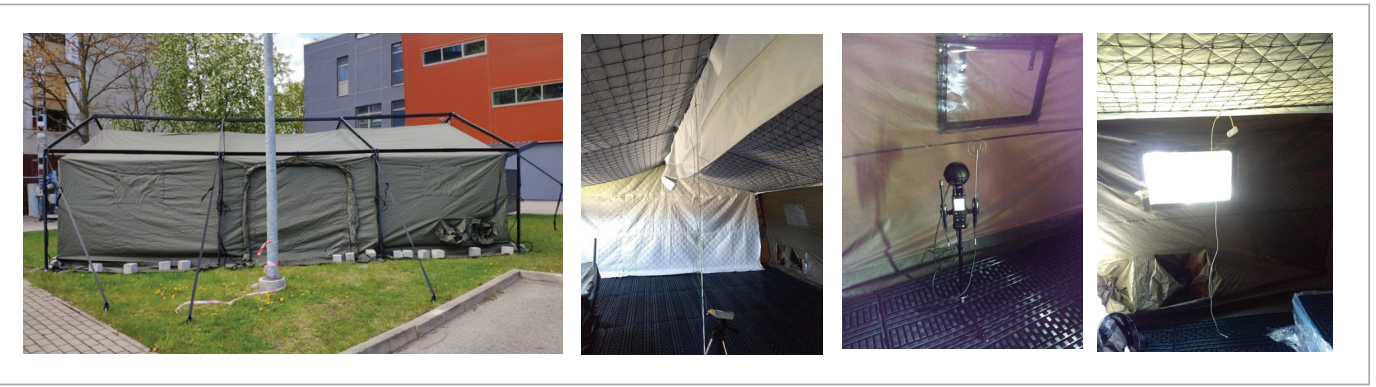

\section{Methods}

Fig. 1

Pictures of the experimental setup and ongoing measurement process 
Accuracy: $\pm 2.5 \%$ from $10 \%$ to $90 \% \mathrm{RH}$ ) placed at the two opposite corners $15 \mathrm{~cm}$ above floor level and $1 \mathrm{~m}$ from walls and TESTO 480 with a full set of measuring probes to measure operative temperature and PMV/PPD which was placed at different locations to see the influence of radiant temperature (see Fig. 2). The outside air parameters were measured using thermocouples while for solar radiation on horizontal plane GBS01 (Measuring range $1400 \mathrm{~W} / \mathrm{m}^{2}$ and accuracy $\pm 5 \%$ plus $\pm 50 \mathrm{~W}$ ) was used. The data was logged with 5-minute increments.

Fig. 2

Schematic layout of the measurement setup in the tent

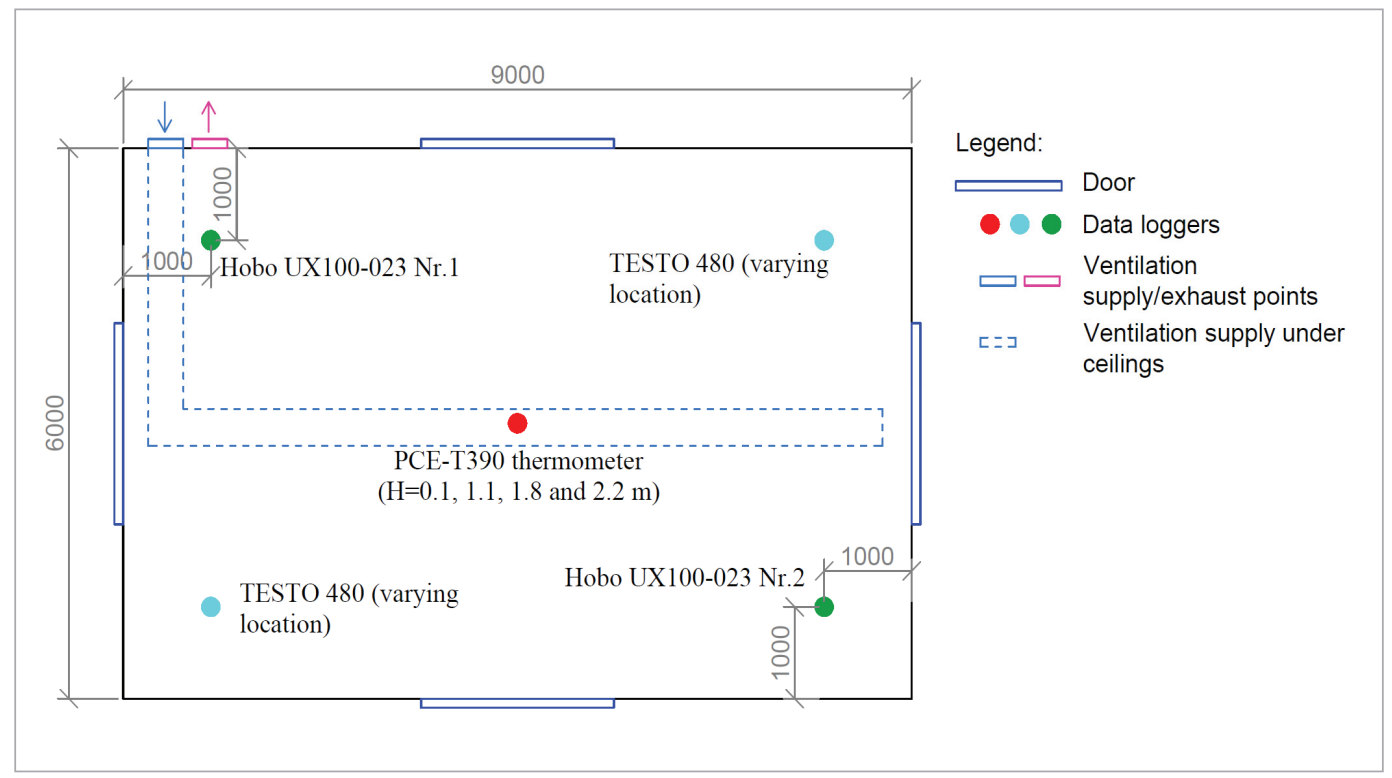

During the experiment, the tent was kept closed and without occupants, so the air exchange was only dependent on natural causes like wind speed. At various moments, the tent was ventilated with precooled air to see how the temperature changes. The air volume for cooling purposes was $350 \mathrm{~m}^{3} / \mathrm{h}$ which was provided by AHU of a Mobile Modular Energy Unit. The temperature of the supply air was in the range of 5 to $15^{\circ} \mathrm{C}$. A more detailed description of the MMEU, operational parameters and the potential energy consumption can be found in a separate publication (Bog-

Fig. 3

Left: Interior of the MMEU; Right: Schematic of the MMEU system
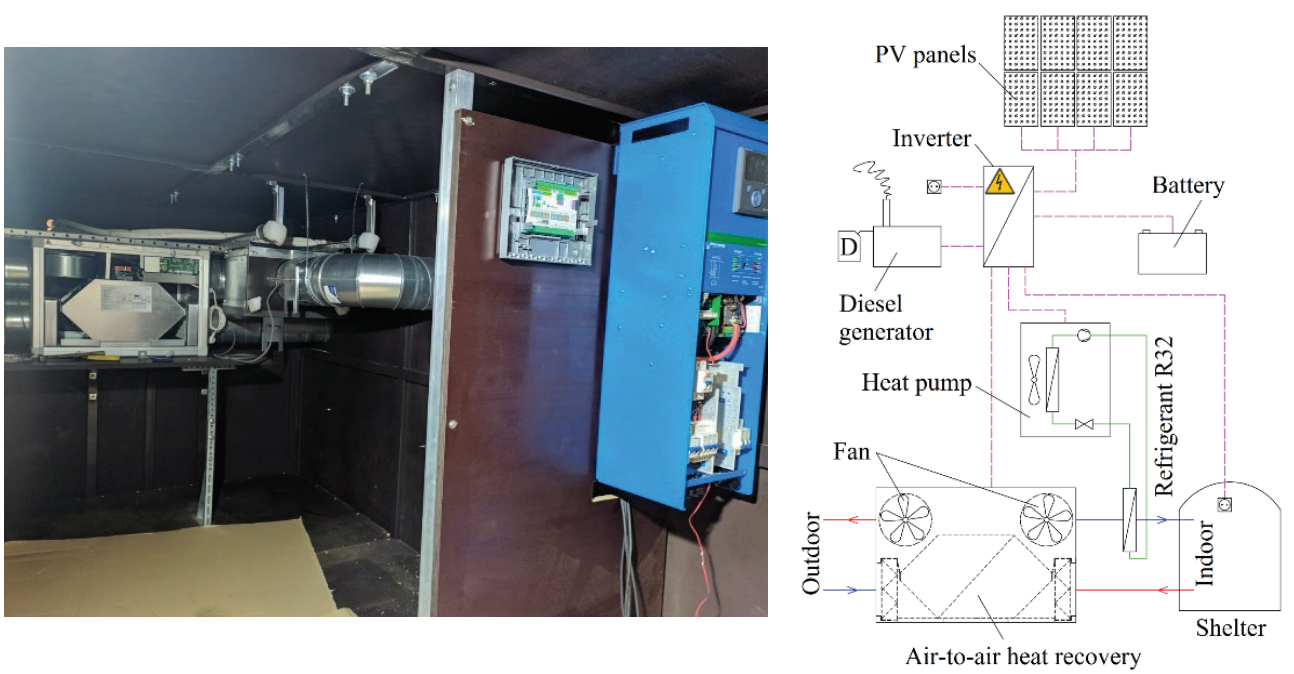
danovics, Raimonds; Borodinecs, Anatolijs; Zemitis, Jurgis; Zajacs 2021). The moments when the environmental system was operating were noted and afterward, these times were excluded from the thermal comfort analysis.

The results of temperature measurements in the tent at a height of $1,1 \mathrm{~m}$ and outside air temperature can be seen in Fig. 4. The data shows the temperature fluctuation during the measurement period. The white gaps without the data occur as the measurement device had to be stopped for maintenance and data reading. The absolute indoor temperature maximum in the measuring period was $+41^{\circ} \mathrm{C}$ while the minimum $+7^{\circ} \mathrm{C}$. The outside temperature was in the range of $+8.1^{\circ} \mathrm{C}$ to $+29.9^{\circ} \mathrm{C}$, with an average value of $+18.4^{\circ} \mathrm{C}$. The average indoor temperature was $+21.1^{\circ} \mathrm{C}$, although it seems reasonable value, the number of hours when the temperature exceeds $+27^{\circ} \mathrm{C}$ is very high -148 h or $20 \%$ from all the measured hours. The calculated degree hours above $+27^{\circ} \mathrm{C}$ are 644 . This means that the tent has serious overheating issues if the same approach as for buildings is applied. The usual guidelines state that the temperature should not exceed the limit temperature $\left(+27^{\circ} \mathrm{C}\right)$ by more than 100 or 150 -degree hours $\left({ }^{\circ} \mathrm{Ch}\right)$ in non-residential buildings, depending on the specific country. The data analysis shows that the indoor temperature rapidly rises approximately $1 \mathrm{~h}$ before the outside air temperature starts to rise. The calculated average temperature difference between indoor temperature and outside temp. is $+2.9^{\circ} \mathrm{C}$, however as the temperature evens out during the night time this value is skewed to zero. At the same time, the temperature indoors exceeds outside air temperature by more than $5^{\circ} \mathrm{C}$ for $522 \mathrm{~h}$ or $71 \%$ of the time. 10 -degree difference is for 412 hours or $56 \%$ of the measurement period.

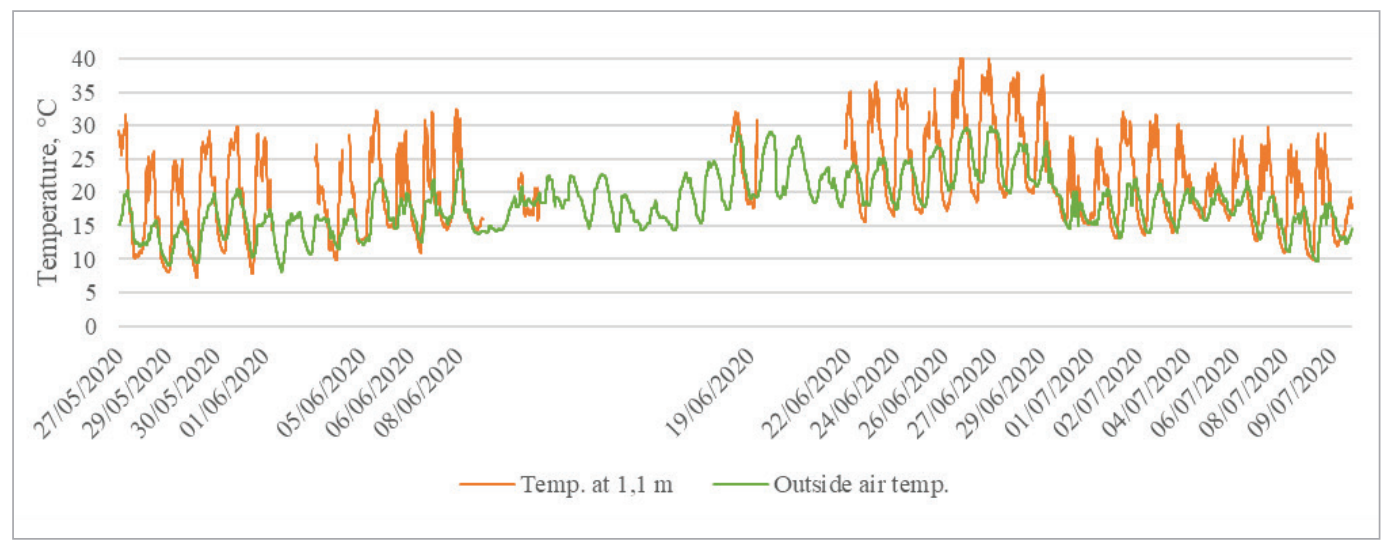

For deeper data analysis and to see how the temperatures are divided depending on height see Fig. 5 which shows results for June $6^{\text {th }}$. It shows all the measured indoor temperatures as well as the outside temperatures according to the official meteo.lv data, locally measured outdoor temperatures also periods of rain are marked. The minimal temperatures for all heights are similar - $14.4^{\circ} \mathrm{C}$ but the maximal $26.5,29.3,32.5,35.0^{\circ} \mathrm{C}$ increase with height.

The data analysis shows that the average temperature difference depending on the height varies throughout the day (Fig. 6). During the night-time, there is no temperature gradient depending on the measurement height while in the daytime it reaches maximal values. The results show that when the temperature rises or falls it happens more rapidly closer to the ceiling. This means that the temperature closer to the floor level is more stable. The temperature fluctuations at $0.1 \mathrm{~m}$ high at the given date are $12.1^{\circ} \mathrm{C}$, while for $1.1,1.8$, and $2.2 \mathrm{~m}$ height $14.9,18.1$ and $20.8^{\circ} \mathrm{C}$, respectively.

As Fig. 5 indicates that there is a temperature fall during the rain period, the data was analyzed to find the effect and whether it is linked with the rain intensity and amount. However, the available data from local meteo stations only provide data about the hourly rain intensity and does not show

\section{Results and Discussion}

Fig. 4

Temperature at $1,1 \mathrm{~m}$ height in the middle of the tent and outside air temperature for the whole measurement period 
Fig. 5

Data of measured

temperature and rain occurrence for 6th June

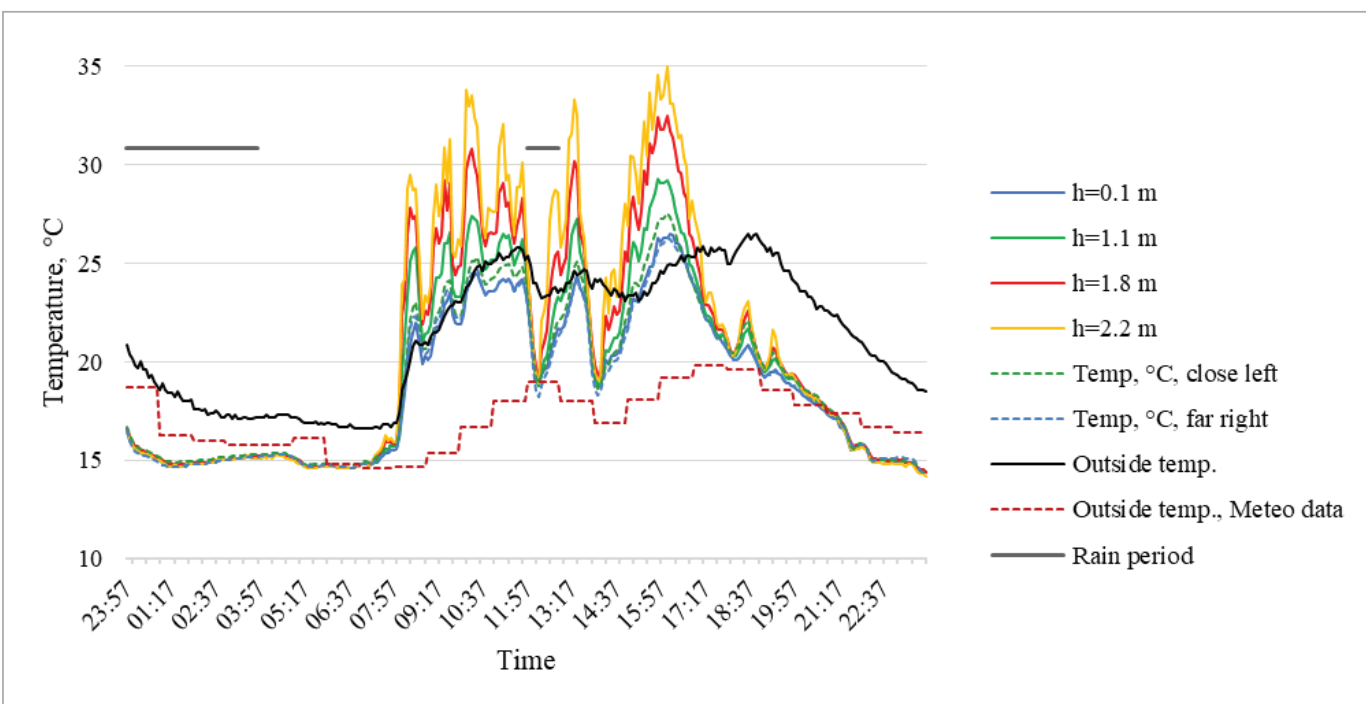

Fig. 6

Temperature gradient changes depending on the height on 6th June
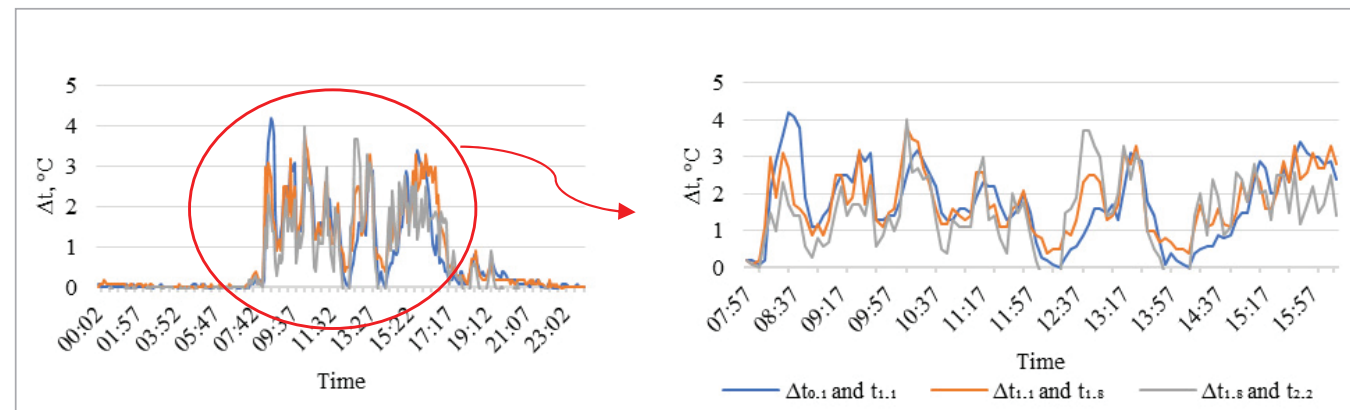

the precise time of the rain period. The logged data was structured and filtered for the periods which had rain. Afterward, the temperature difference which occurs during the rain period was calculated, and the respective precipitation was noted. The results are shown in Fig. 7. The positive values show that the temperature decreases in a given hour, while the negative that it increases. The data are shown for indoor temperatures measured at 1,1 m height. In 11 of 19 cases, the temperature decreased. A single point stands out which shows that the temperature in a one-

Fig. 7

Change in indoor air temperature depending on precipitation rate

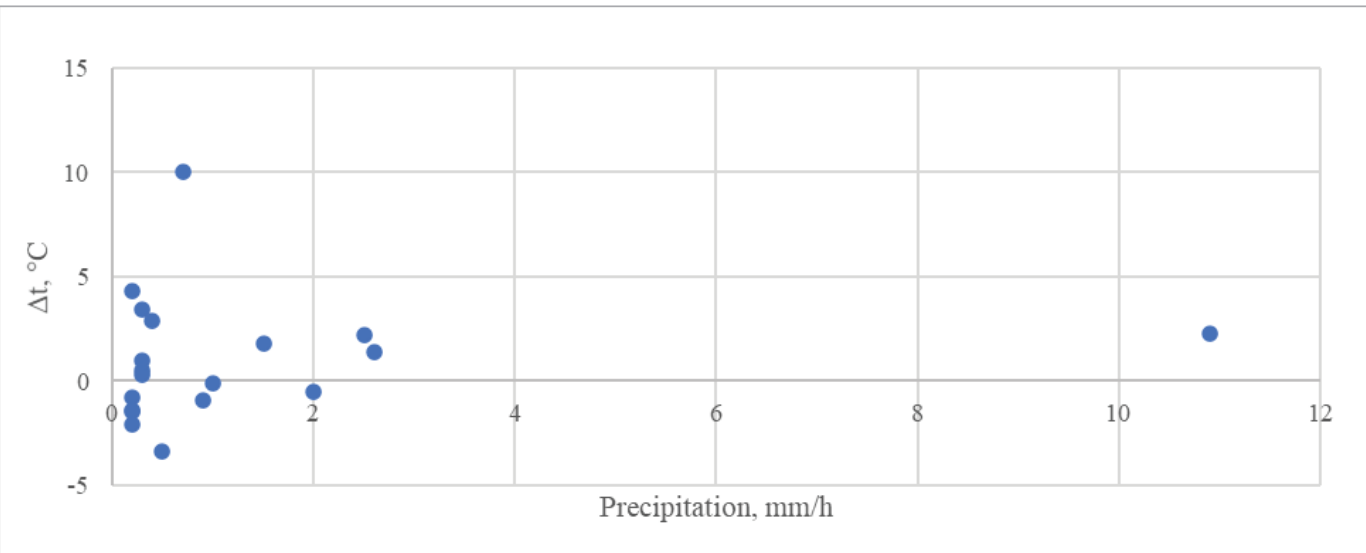


hour interval decreased by 10 degrees. It happened during a hot summer day on June $13^{\text {th }}$ when in time from 15:20 to 16:10 the temperature decreased from 31.8 to 21.8 degrees. On average the temperature decreased by only 1 degree.

As the results indicate there are no direct relations between the precipitation rate and temperature change. This could be explained by the fact that the temperature is affected not only by the occurrence of rain but also by factors like outside temperature, the indoor temperature at the start of the rain, solar radiance, wind, etc. For the analysis of the results, only the cases when rain happened during the daytime (from 12:00 to 20:00) were looked at. As for the night period, the indoor temperature is already low, and the cooling effect of the rain cannot take place.

The indoor air temperatures and how they change during the rain periods are shown in Fig. 8. This figure in higher detail shows the adiabatic cooling effect. It can be seen that in 10 of 13 occurrences or 77 percent of rain periods the temperature, at least for some time, dropped. The information about the rain was available with a time interval of 1 hour, therefore the temperature increase could be explained by the fact that the rain lasted for a shorter amount of time, but it was not noted.

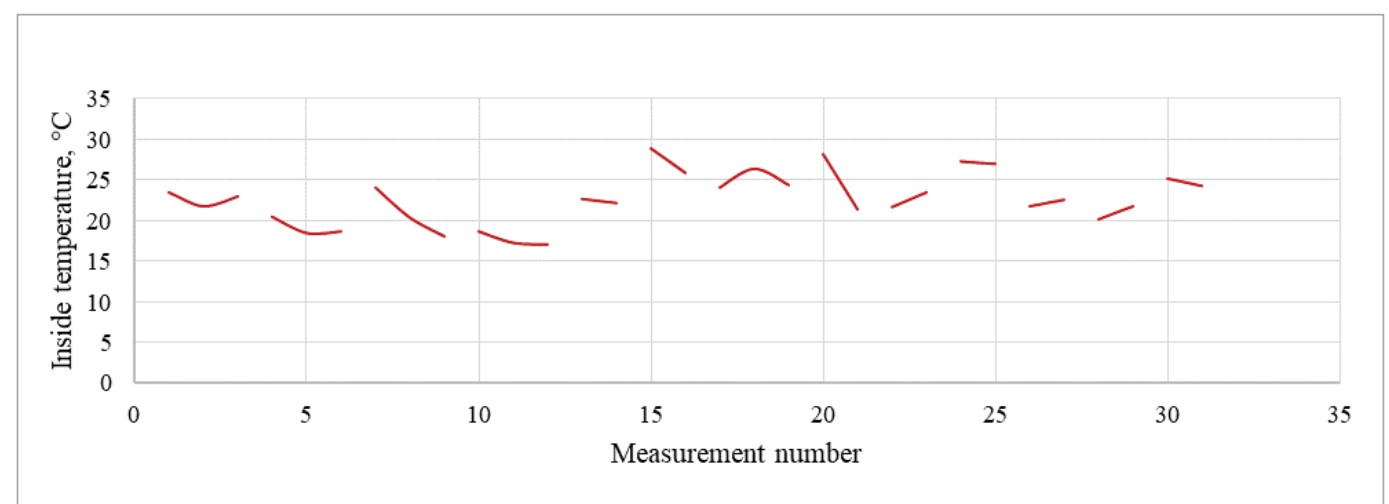

To see how the thermal comfort varies in the temporary shelter the measured predicted mean vote (PMV) was analyzed. The PMV more specifically indicates the thermal comfort of the premise than just air temperature. For the PMV calculations, it was assumed that the persons located in the tent are with a clothing level of 1 CLO and activity of 1 met. Fig. 9 shows the calculated PMV in the period from $2^{\text {nd }}$ to $14^{\text {th }}$ July. The results shown that the values for given time period the PMV value was in divided by the ranges as follows: 2 to $3-4 \% ; 1$ to $2-12 \%$; 0 to $1-22 \%, 0$ to $-1-22 \%$, -1 to $-2-23 \%,-2$ to $-3-18 \%$. This means that it was outside the reasonable range from -1 to 1 for $57 \%$ of the time.

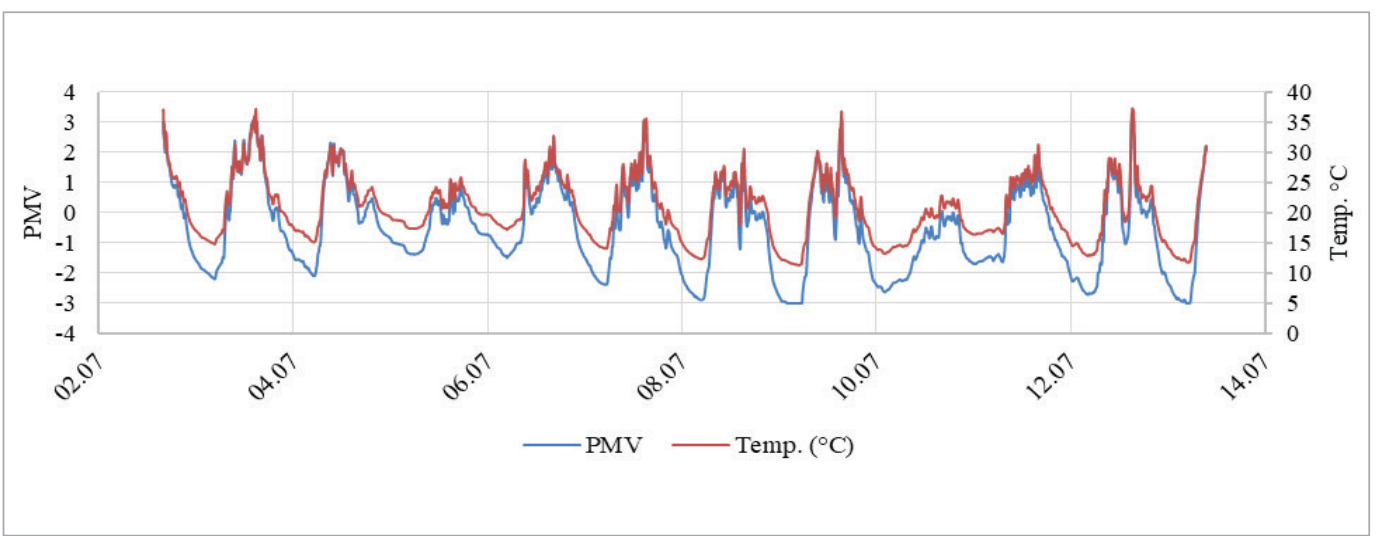

Fig. 8

Change in indoor air temperature during the precipitation

Fig. 9

Values of PMV in the tent from 2nd to 14 th July 
To see how the PMV change depending on the specific location in the tent, for some time the measuring device was placed close to the external envelope of the tent. The results are shown in Fig. 10. The results show that the thermal comfort is at a very low level as for $63 \%$ of the time it is outside the range of +1 to -1 . To see if the shelter envelope heats up and emits radiation to inside the globe and indoor air temperatures are compared in Fig. 11. Results show that the temperatures are close with an average difference of $0.5^{\circ} \mathrm{C}$ and maximal temperature difference $+1.8^{\circ} \mathrm{C}$ and $-1.7^{\circ} \mathrm{C}$. From 907 measuring points, 715 or $79 \%$ indicate that the globe temperature is higher.

Fig. 10 Calculated values of PMV in the tent from 19th to 23rd July

Fig. 11

Indoor air and globe temperature in the tent from 19th to 23rd July
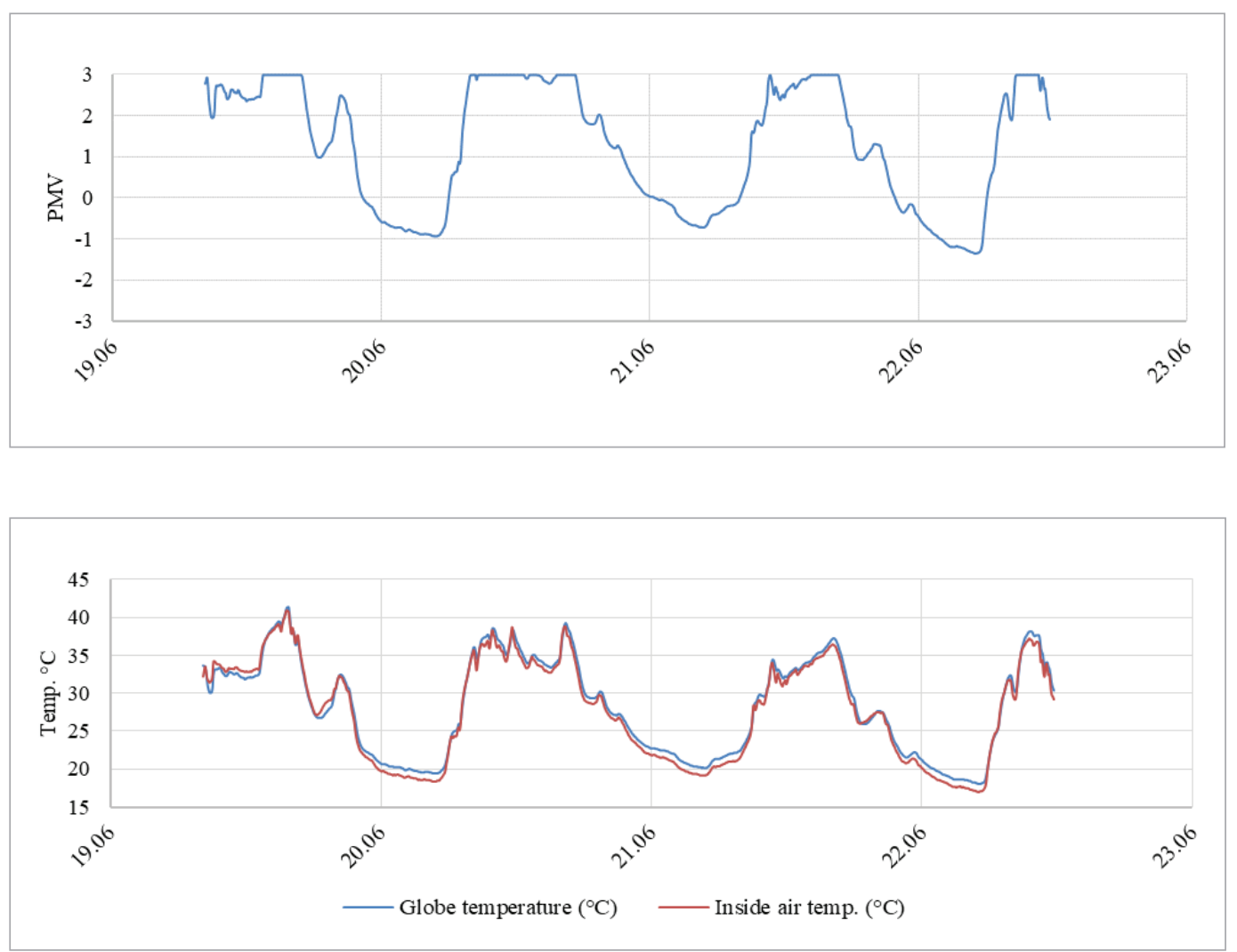

The results of temporary shelter thermal parameter measurements show that the temperature in the tent changes rapidly during the daytime and can reach $+41^{\circ} \mathrm{C}$ while the minimum was $+7^{\circ} \mathrm{C}$. The average temperature was $+21.1^{\circ} \mathrm{C}$. The high temperature variance between day and nighttime is due to small thermal mass as the temporary shelter is made of very light material. Therefore, to maintain a comfortable indoor temperature it would be necessary both to heat and cool the shelter even during the warm period of the year. Sometimes this could be overlooked in cases when a rapid need for a larger amount of temporary shelters is necessary would it be in case of pandemic, migrant crisis or any other.

The difference between the temperatures at various heights during daytime reached 5.6, 5, and $6,7^{\circ} \mathrm{C}$ between $\mathrm{t}_{0,1}$ and $\mathrm{t}_{1,1}, \mathrm{t}_{1,1}$ and $\mathrm{t}_{1,8}, \mathrm{t}_{1,8}$ and $\mathrm{t}_{2,2}$ respectively. The maximal temperature difference between the temperature at 0,1 and 2,2 meters reached $12,7^{\circ} \mathrm{C}$. This indicates about air stratification which is caused by the lack of air exchange or air movement. In the case of air mixing, it would be expected that the temperatures even out and this could be utilized to increase thermal comfort during nighttime. 
The globe temperature analysis showed that the heat radiation from external walls does not affect the operative temperature noticeably. The average difference between the global temperature and indoor air temperature difference was only $0.5^{\circ} \mathrm{C}$. The PMV study, which is based on the operative temperature as well as air velocity and relative humidity, shows that for $60 \%$ of the time the PMV value is outside the range of -1 to +1 . This indicates that the tent produces very poor thermal comfort parameters. From this time PMV value was above +1 for $12 \%$ of the time and below -1 for $48 \%$ of the time. This indicates that during the night time even during the summertime persons would feel cold without an extra level of insulation. The results partially coincide with the existing studies as they also state the high PPD of persons located in temporary shelters. Although these experiments were performed in Indonesia and Italy, countries with different climatic conditions than Latvia.

The study also tested the hypothesis that precipitation noticeably affects indoor temperature. The results showed that during the rain time the temperature decreases for 77 percent of rain occurrences. The influence on temperature is noticeable and, in most cases, close to $5^{\circ} \mathrm{C}$. However, the temperature change was not related to the precipitation amount. Also, the average temperature decrease was only $1^{\circ} \mathrm{C} \pm 2.96$, but for a specific case, even a $10^{\circ} \mathrm{C}$ decrease was reached.

The study is limited by the fact that in a real case scenario the temporary shelter would be occupied by persons. This would influence the door opening and therefore the air circulation in the tent. Due to this, the expected indoor temperatures would be lower during the daytime. As for the nighttime, the indoor temperature should be higher in the case of persons using it, as they would be emitting heat from their bodies. The study regarding the temperature drop caused by precipitation should also be continued and improved, as during the measurement period there was a small number (13) of rain occurrences during the daytime. For future studies thermal comfort of temporary shelter equipped with MMEU could be carried out, to study the impact of such a device and its potential to increase thermal comfort.

\section{Acknowledgment}

This work has been supported by the European Regional Development Fund within the Activity 1.1.1.2 "Post-doctoral Research Aid" of the Specific Aid Objective 1.1.1 "To increase the research and innovative capacity of scientific institutions of Latvia and the ability to attract external financing, investing in human resources and infrastructure" of the Operational Programme "Growth and Employment" (No. 1.1.1.2/VIAA/1/16/033).

Albadra, D., M. Vellei, D. Coley, and J. Hart. 2017. "Thermal Comfort in Desert Refugee Camps: An Interdisciplinary Approach." Building and Environment 124. https://doi.org/10.1016/j.buildenv.2017.08.016

Bilous, I. Yu, V. I. Deshko, and I. O. Sukhodub. 2020. "Building Energy Modeling Using Hourly Infiltration Rate." Magazine of Civil Engineering 96 (4). https:// doi.org/10.18720/MCE.96.3.

Bogdanovics, Raimonds; Borodinecs, Anatolijs; Zemitis, Jurgis; Zajacs, Aleksandrs. 2021. "Using a Mobile Modular Energy Unit With PV Panels For Heating." ASHRAE Journal 63 (4): 38-40,42-44,46.

Bouden, C., and N. Ghrab. 2005. "An Adaptive Ther- mal Comfort Model for the Tunisian Context: A Field

\section{References} doi.org/10.1016/j.enbuild.2004.12.003

Cena, Krzysztof, Nicole Davey, and Tamara Erlandson. 2003. "Thermal Comfort and Clothing Insulation of Resting Tent Occupants at High Altitude." Applied Ergonomics 34 (6): 543-50. https://doi.org/10.1016/ S0003-6870(03)00084-X

Cornaro, Cristina, Dalila Sapori, Francesco Bucci, Marco Pierro, and Corrado Giammanco. 2015. "Thermal Performance Analysis of an Emergency Shelter Using Dynamic Building Simulation." Energy and Buildings 88: 122-34. https://doi.org/10.1016/j. enbuild.2014.11.055 
Crawford, C, P Manfield, and A McRobie. 2005. "Assessing the Thermal Performance of an Emergency Shelter System." Energy and Buildings 37 (5): 471 83. https://doi.org/10.1016/j.enbuild.2004.09.001

Dear, R. J. De, T. Akimoto, E. A. Arens, G. Brager, C. Candido, K. W.D. Cheong, B. Li, et al. 2013. “Progress in Thermal Comfort Research over the Last Twenty Years." Indoor Air. https://doi.org/10.1111/ ina. 12046

Dobravalskis, Mantas, Lina Šeduikyte, and Ugne Didz lariekyte. 2020. "Field Measurements and CFD Simulation of a Room in an Elderly Care Center in Lithuania to Evaluate Air Quality and Thermal Comfort." In E3S Web of Conferences. Vol. 172. https:// doi.org/10.1051/e3sconf/202017206005

Gooijer, Henk, Manicka Velan, Irfan Esen, Sven Kamphuis, Richard Groeneveld, Pramod Agrawal, and Ger Brinks. 2019. "THERMAL COMFORT OF TEXTILES FOR TENT APPLICATION." In AUTEX2019-19th World Textile Conference on Textiles at the Crossroads, 1-6. Ghent, Belgium.

Hoof, J. Van. 2008. "Forty Years of Fanger's Model of Thermal Comfort: Comfort for All?" Indoor Air 18 (3). https://doi.org/10.1111/j.1600-0668.2007.00516.x

Huang, Jianhua. 2008. "Prediction of Air Temperature for Thermal Comfort of People Using Sleeping Bags: A Review." International Journal of Biometeorology. https://doi.org/10.1007/s00484-0080180-5

IDMC. 2017. “International Displacement Monitoring Centre Database." https://www.internal-displacement.org/database.

Kim, Jeong-Gook, Junghun Lee, Byung-Lip Ahn, Hwayeon Shin, Seunghwan Yoo, Cheol-Yong Jang, Doosam Song, and Jonghun Kim. 2015. "Indoor Thermal Environment of Temporary Mobile Energy Shelter Houses (MeSHs) in South Korea." Energies 8 (10): 11139-52. https://doi.org/10.3390/ en81011139

Kuusk, Kalle, Ahmed Kaiser, Nicola Lolli, Jan Johansson, Tero Hasu, Anne Gunnarshaug Lien, Endrik Arumägi, et al. 2019. “Energy Performance, Indoor Air Quality and Comfort in New Nearly Zero Energy Day-Care Centres in Northern Climatic Conditions." Journal of Sustainable Architecture and Civil Engineering 24 (1). https://doi.org/10.5755/ j01.sace.24.1.23228

Manfield, Pete, Joseph Ashmore, and Tom Corsellis. 2004. "Design of Humanitarian Tents for Use in Cold Climates." Building Research
I\& Information 32 (5): 368-78. https://doi. org/10.1080/0961321042000220990

Matusiak, Malgorzata. 2010. “Thermal Comfort Index as a Method of Assessing the Thermal Comfort of Textile Materials." Fibres and Textiles in Eastern Europe 18: 45-50.

Nicol, Fergus, Michael Humphreys, and Susan Roaf. 2012. Adaptive Thermal Comfort: Principles and Practice. Adaptive Thermal Comfort: Principles and Practice. https://doi. org/10.4324/9780203123010

Obyn, S, G van Moeseke, and V Virgo. 2015. “Thermal Performance of Shelter Modelling: Improvement of Temporary Structures." Energy and Buildings 89: 170-82. https://doi.org/10.1016/j.enbuild.2014.12.035

Poschl, Ruth A. 2019. "Modelling the Thermal Comfort Performance of Tents Used in Humanitarian Relief."

Potangaroa, Regan, and Max Hynds. 2008. "Thermal Comfort Tools for Emergency Shelter in Major Disasters." In International Conference on Building Education and Research (BEAR), 1457-72. Salford.

Rachel, Battilana. 2001. "Design of Cold Climate Temporary Shelter for Refugees."

Rupp, Ricardo Forgiarini, Natalia Giraldo Vásquez, and Roberto Lamberts. 2015. "A Review of Human Thermal Comfort in the Built Environment." Energy and Buildings. https://doi.org/10.1016/j.enbuild.2015.07.047

Susanti, Lusi. 2015. "Thermal Comfort Evaluation of Emergency Tent Using PMV and PPD Model." In International MultiConference of Engineers and Computer Scientists, 2:1-6. Hong Kong.

Thapa, Samar, Ramkishore Singh, Mahesh Bundele, Sheetal Thapa, George Thadathil, and Yogesh Kr. Jakhar. 2021. "Study of Thermal Comfort in the Residents of Different Climatic Regions of India-Effect of the COVID-19 Lockdown." Indoor Air 31 (3): 899-917. https://doi.org/10.1111/ina.12778

UNHCR. 2014. "Statistical Yearbook 2014." www.unhcr.org/statisticalyearbook/2014-annex-tables.zip. UNHRC. 2021. "Refugee Data Finder." 2021. https:// www.unhcr.org/refugee-statistics/.

Yang, Hao, Yingni Jiang, Jingbo Liu, and Zhengguo Gong. 2016. "The Field Investigation on Thermal Comfort of Tent in Early Autumn of Tianjin." MATEC Web of Conferences 61: 2-5. https://doi. org/10.1051/matecconf/20166101001 


\section{JURGIS \\ ZEMITIS}

Associate Professor

Riga Technical University, Heat, Gas and Water Technology Institute

\section{Main research area}

Energy performance of buildings, ventilation, heating

\section{Address}

Kispalas street 6A, LV1048, Riga, Latvia Tel.+ 37128369940

E-mail: jurgis.zemitis@ rtu.lv

\section{ANATOLIJS BORODINECS \\ Professor \\ Riga Technical University, Heat, Gas and Water Technology Institute}

\section{Main research area}

Energy performance of buildings, HVAC systems, thermal bridges

\section{Address}

Kispalas street 6A, LV1048, Riga, Latvia Tel.+ 37126079655

E-mail: anatolijs. borodinecs@rtu.lv

\section{RAIMONDS BOGDANOVICS}

Researcher

Riga Technical University, Heat, Gas and Water Technology Institute

Main research area

Energy performance of buildings, Centralized heating systems, renewable resources

\section{Address}

Kispalas street 6A, LV1048, Riga, Latvia

Tel.+ 37125450508

E-mail: Raimonds. bogdanovics@rtu.lv

\section{ALEKSANDRS} GEIKINS

Researcher

Riga Technical University, Heat, Gas and Water Technology Institute

\section{Main research area}

Energy performance of buildings, HVAC systems

\section{Address}

Kispalas street 6A, LV1048, Riga, Latvia

Tel.+ 37127262222

E-mail: Aleksandrs.

Geikins@rtu.lv
About the Authors 